\title{
CALOGÊNESE EM ÓVULOS DE ESPÉCIES E VARIEDADES DE CITRUS ${ }^{1}$
}

\author{
ROBERTO PEDROSO DE OLIVEIRA ${ }^{2}$, GENI CARMEN ZANOL ${ }^{3}$, \\ JOAQUIM ALVES GONÇALVES ${ }^{4}$, WALTER DOS SANTOS SOARES FILHO
}

\begin{abstract}
RESUMO - A Embrapa Mandioca e Fruticultura vem realizando ações de pesquisa visando à obtenção de híbridos somáticos de citros, particularmente porta-enxertos, melhor adaptados às condições tropicais de cultivo brasileiras que as variedades atualmente em uso. Como objetivo principal, busca-se a seleção de genótipos tolerantes à seca e ao alumínio, tolerantes/resistentes a gomose de Phytophthora e tristeza dos citros, além de adaptados a altas densidades populacionais. Como fontes de protoplastos, vêm sendo utilizadas as tangerinas- 'Cleópatra', 'Sunki' e 'Swatow', limões- 'Cravo Santa Cruz' e 'Santa Bárbara', 'Volkameriano' e 'Rugoso Mazoe', laranja 'Hamlin CNPMF 04' e 'CNPMF 20', laranjas-azedas 'Comum' e 'Narrow Leaf', citrange-'Troyer', Citrus amblycarpa e Microcitrus papuana. O estudo concentrou-se na etapa de obtenção e cultivo de calos embriogênicos. Foram utilizados óvulos extraídos de frutos imaturos, empregando-se como meio de cultura o MT, adicionando-se 50 g.L.-1 de sacarose e $500 \mathrm{mg} . \mathrm{L}^{-1} \mathrm{de}$ extrato de malte e solidificando com 7 g...-1 de ágar. Em geral, a indução de calos nas variedades estudadas ocorreu entre a $6^{\mathrm{a}}$ e a $8^{\mathrm{a}}$ semana de cultivo, com maior precocidade na laranja-'Hamlin', sendo que, em limão-'Cravo', laranja-'Hamlin', tangerinas-'Cleópatra' e 'Swatow' e citrange-'Troyer', a porcentagem de formação de calos foi igual ou superior a 50\%, destacando-se a tangerina- 'Cleópatra' com um porcentual próximo a $70 \%$ de calogênese.
\end{abstract}

Termos para indexação: Embriogênese, Citrus spp., Poncirus trifoliata, Microcitrus papuana.

\section{CALLUS INDUCTION FROM CITRUS SPECIES AND VARIETIES}

\begin{abstract}
Embrapa Cassava \& Fruits Research with citrus aim at obtaining somatic hybrids, particularly rootstocks, better adapted to the Brazilian tropical cultivation conditions than the varieties currently in use. The main objectives are the selection of genotypes tolerant to drought and aluminum toxicity, tolerant/resistant to Phytophthora foot rot and citrus tristeza virus, besides being well adapted to high planting densities. The following varieties have being used as protoplast sources: Cleopatra, Sunki and 'Swatow' mandarins, Rangpur lime selections Santa Cruz and Santa Bárbara, Volkamer lemon and Mazoe rough lemon, 'Hamlin' sweet orange selections CNPMF 04 and CNPMF 20, sour orange selections Common and Narrow Leaf, Troyer citrange, Citrus amblycarpa and Microcitrus papuana. The study focused on obtaining and cultivating embryogenic calli. Ovules taken from immature fruits were used in a modified MT culture medium, containing $50 \mathrm{~g} . \mathrm{L}^{-1}$ of sucrose and $500 \mathrm{mg} . \mathrm{L}^{-1}$ of malt extract, solidified with 7 g.L. $\mathrm{L}^{-1}$ of agar. In general, callus induction in the studied varieties was observed between the $6^{\text {th }}$ and the $8^{\text {th }}$ weeks of cultivation. In the Rangpur lime, 'Hamlin' sweet orange, Cleopatra and 'Swatow' mandarins and Troyer citrange, the percentage of callus formation was equal or superior to $50 \%$. The Cleopatra mandarin stood out with a percentage near $70 \%$ of callus formation.
\end{abstract}

Index terms: Embryogenesis, Citrus spp., Poncirus trifoliata, Microcitrus papuana.

\section{INTRODUÇÃO}

A fusão de protoplastos de variedades comerciais de Citrus com aqueles de espécies pertencentes a gêneros afins a este, como Microcitrus e Eremocitrus, de reconhecido valor adaptativo a ambientes sujeitos a estresses, apresenta grandes perspectivas sob o ponto de vista do melhoramento genético dos citros, particularmente no tocante à obtenção de novos portaenxertos.

Por serem alotetraplóides, tais híbridos mantêm as ligações gênicas presentes nos pais, devido à ausência de segregação meiótica. Desse modo, os genes deletérios recessivos presentes nas variedades parentais permanecem sem expressão, escondidos sob uma condição heterozigótica, dando-se o contrário com as características controladas por genes dominantes ou codominantes, cuja possibilidade de manifestação nos híbridos é preservada.

Vários autores têm conseguido híbridos somáticos interespecíficos (Grosser et al., 1989 e 1991; Kobayashi et al., 1988; Oghawara et al., 1989; Tusa et al., 1990), híbridos somáticos intergenéricos, de espécies sexualmente compatíveis (Deng et al., 1991; Grosser et al., 1988) e de espécies incompatíveis (Grosser et al., 1990a ,1990b e 1991).

O limão-'Rugoso' (C. jambhiri Lush.) e o limão'Volkameriano' (C. volkameriana Ten. et Pasq.) têm despertado grande interesse por serem altamente produtivos e tolerantes à tristeza e à seca, porém têm a desvantagem de serem suscetíveis

1 Trabalho $\mathrm{n}^{\circ}$ 162/2000. Recebido: 24/07/2000. Aceito para publicação: 22/05/2001.

2 Eng $^{\circ}$. Agr ${ }^{\circ}$. Pesquisador Embrapa Clima Temperado, CP 453, 96001-970, Pelotas, RS.

$3 \mathrm{Eng}^{\circ}$. $\mathrm{Agr}^{\circ}$, em curso de pós-graduação em nível de doutorado, Università S. Anna Pisa, Itália.

4 Acadêmico da Escola de Agronomia da Universidade Federal da Bahia, bolsista PIBIC-CNPq, 44380-000, Cruz das Almas, BA.

$5 \mathrm{Eng}^{\circ}$. Agr ${ }^{\circ}$. Pesquisador Embrapa Mandioca e Fruticultura, bolsista PQ-CNPq, CP 007, 44380-000, Cruz das Almas, BA. 
ao declínio dos citros. A tangerina- 'Cleópatra' (C. reshni Hort. ex Tan.), por sua vez, embora tolerante ao declínio, apresenta o inconveniente de que as copas nela enxertadas possuem um longo período vegetativo (Castle, 1987). As laranjeiras-doces [C. sinensis (L.) Osb.] também são tolerantes ao declínio (Castle et al., 1993), mas sua utilização como porta-enxertos tem sido reduzida drasticamente devido à alta suscetibilidade à gomose de Phytophthora que manifestam. Assim, a hibridação somática da tangerina- 'Cleópatra' com os limões-'Rugoso' e 'Volkameriano' ou com laranjas-doces poderá originar portaenxertos vigorosos, produtivos e resistentes ao declínio (Louzada et al., 1992). Outro exemplo poderia incluir a hibridação somática entre a laranja-'Azeda' (C. aurantium L.) com a tangerina'Cleópatra', reunindo as características de alta produtividade e qualidade de frutos, longevidade, resistência à geada, à seca, ao declínio e à gomose, além de boa adaptação a uma grande diversidade de solos da primeira, com a tolerância à tristeza presente na citada tangerina (Louzada et al., 1992).

Os calos nucelares embriogênicos podem ser obtidos a partir do cultivo de óvulos abortivos, óvulos não fertilizados, óvulos inteiros fertilizados, ou de nucelos (Gmitter Jr. \& Moore, 1986). A esse respeito, dentre os fatores que mais influenciam a indução de calos nucelares embriogênicos, destacam-se as condições do ambiente em que a planta se desenvolvem, o genótipo, a idade dos explantes e os componentes do meio de cultura (Spiegel-Roy \& Kochba, 1980 e Moore, 1985).

Este trabalho faz parte das atividades do Programa de Melhoramento Genético de Citros da Embrapa Mandioca e Fruticultura, cujos objetivos incluem a obtenção de novos portaenxertos melhor adaptados às condições tropicais de cultivo brasileiras, enfatizando-se a tolerância à seca e ao alumínio, tolerância/resistência a doenças, a exemplo da gomose de Phytophthora e tristeza dos citros, além da adaptação a altas densidades populacionais. Neste contexto, pretendeu-se, com o estudo aqui apresentado, ajustar e avaliar procedimentos metodológicos prévios ao isolamento de protoplastos de citros, visando à obtenção de híbridos somáticos interespecíficos e intergenéricos.

Espera-se que os híbridos obtidos por esse processo apresentem características complementares provenientes das variedades doadoras de protoplastos, variedades estas muitas vezes relacionadas a espécies pertencentes a diferentes grupos (pools) gênicos, entre as quais a troca de genes mediante hibridação convencional pode ser impedida por barreiras reprodutivas.

\section{MATERIAL E MÉTODOS}

A pesquisa foi conduzida no Laboratório de Biotecnologia Vegetal da Embrapa Mandioca e Fruticultura, em Cruz das Almas - BA, utilizando as seguintes variedades: tangerina-Cleópatra, Sunki (C. sunki Hort. ex Tan.), e Swatow (C. reticulata Blanco), limões-Cravo (C. limonia Osb.) seleções Santa Cruz e Santa Bárbara, Volkameriano e Rugoso Mazoe, laranjadoce Hamlin seleções CNPMF 04 e 20, laranja-Azeda seleções Comum e Narrow Leaf, citrange (C. sinensis $\mathrm{x}$ P. trifoliata) Troyer, C. amblycarpa Ochse e Microcitrus papuana.

Os frutos empregados na extração de óvulos não fertilizados foram obtidos de plantas do Banco Ativo de Germoplasma de Citros da Embrapa Mandioca e Fruticultura, sendo coletados imaturos.

Depois de extraídos das sementes dos frutos, sob condições assépticas, os óvulos não fertilizados foram tratados em solução contendo três partes de água destilada esterilizada e uma parte de hipoclorito de sódio ( $2 \%$ de cloro ativo), por 12 minutos. Posteriormente, foram feitas três lavagens com água destilada esterilizada (Spiegel-Roy \& Vardi, 1984), visando a eliminar resíduos de hipoclorito.

Em seguida, os óvulos foram incubados em meio de cultura, sob condições de escuro, a $27 \pm 1^{\circ} \mathrm{C}$, de modo a induzir a formação de calos embriogênicos. $\mathrm{O}$ meio de cultura compreendeu os sais minerais e vitaminas do meio MT (Murashige \& Tucker, 1969), adicionado de 50 g.L. $\mathrm{L}^{-1}$ de sacarose e $500 \mathrm{mg} . \mathrm{L}^{-1}$ de extrato de malte, conforme Kochba \& SpiegelRoy (1973), solidificado com 7 g.L $\mathrm{L}^{-1}$ de ágar. O pH foi ajustado para 5,7-5,8 e o meio foi esterilizado em autoclave à temperatura de $121^{\circ} \mathrm{C}$, durante 40 minutos. As avaliações relativas à formação de calos foram realizadas em intervalos semanais.

\section{RESULTADOS E DISCUSSÃO}

Em geral, a indução de calos nas variedades estudadas ocorreu entre a $6^{\mathrm{a}}$ e a $8^{\mathrm{a}}$ semana de cultivo de óvulos. Resultados semelhantes foram relatados por Kochba et al. (1972), que obtiveram calos e/ou embrióides utilizando como fonte de explantes óvulos de laranja-'Valência' (C. sinensis) e pomelo'Marsh Seedless' (C. paradisi Macf.). No tocante à laranja'Hamlin CNPMF 20', entretanto, a formação de calos aconteceu entre a $3^{\mathrm{a}}$ e a $4^{\mathrm{a}}$ semana após o estabelecimento in vitro dos explantes no meio de cultura. Segundo Moore (1985), essas diferenças em relação ao período de cultivo necessário à ocorrência de embriogênese são devidas ao efeito do genótipo, idade do explante e meio de cultura utilizado.

A porcentagem de óvulos que formaram calos variou bastante entre as 14 variedades estudadas. Dentre as 10 variedades para as quais se obteve calogênese, a porcentagem de formação de calos foi igual ou superior a $50 \%$ em cinco delas, a saber: tangerina-Cleópatra $(66,0 \%)$, limão-Cravo Santa Cruz $(60,0 \%)$, laranja-Hamlin CNPMF $20(58,0 \%)$, citrange-Troyer $(55,5 \%)$, laranja-Hamlin CNPMF $04(51,6 \%)$ e tangerina-Swatow $(50,0 \%)$, conforme se verifica na Tabela 1 e Figura 1 . Oliveira et al. (1994), trabalhando com diferentes meios de cultivo, também verificaram que, independentemente do meio utilizado, a tangerina- 'Cleópatra' apresentou elevada formação de calos $(48,8 \%)$ e menor formação de embrióides $(0 \%)$. Esses resultados indicam uma alta porcentagem de embriogênese, uma vez que este processo normalmente ocorre em apenas $0 \%$ a $25 \%$ dos explantes, conforme Vardi et al. (1982), Moore (1985) e Gmither \& Moore (1986).

Em geral, no conjunto de variedades estudadas, as tangerinas e laranjas apresentaram maior formação de calos. Estes estão sendo subcultivados em meio MT + BAP acrescido de 500 mg. $L^{-1}$ de extrato de malte, visando a sua adaptação e multiplicação, encontrando-se os mesmos, no momento, entre o $2^{\circ}$ e o $3^{\circ}$ subcultivo. Nos limões-'Cravo Santa Bárbara', 'Volkameriano' e 'Rugoso Mazoe', bem como em M. papuana, 
TABELA 1 - Obtenção de calos embriogênicos em citros a partir de óvulos não fertilizados estabelecidos em meio de cultura MT, com modificações. Embrapa Mandioca e Fruticultura. Cruz das Almas-BA, 1999.

\begin{tabular}{lccc}
\hline Variedades & $\begin{array}{c}\mathbf{N}^{\mathbf{0}} \text { de óvulos } \\
\text { estabelecidos }\end{array}$ & $\begin{array}{c}\mathbf{N}^{\mathbf{0}} \mathbf{d e} \text { óvulos que } \\
\text { formaram calos }\end{array}$ & $\begin{array}{c}\text { \% de óvulos que } \\
\text { formaram calos }\end{array}$ \\
\hline Laranja-Azeda Comum & 18 & 01 & 5,5 \\
Laranja-Azeda Narrow Leaf & 24 & 08 & 33,3 \\
Laranja-Hamlin CNPMF 04 & 60 & 24 & 51,6 \\
Laranja-Hamlin CNPMF 20 & 24 & 14 & 58,0 \\
Limão-Cravo Santa Bárbara & 36 & 0 & 0,0 \\
Limão-Cravo Santa Cruz & 10 & 06 & 60,0 \\
Limão-Rugoso Mazoe & 30 & 0 & 0,0 \\
Limão-Volkameriano & 48 & 0 & 0,0 \\
Tangerina-Cleópatra & 06 & 04 & 66,0 \\
Tangerina-Sunki & 24 & 10 & 41,6 \\
Tangerina-Swatow & 12 & 06 & 50,0 \\
Citrange-Troyer & 36 & 20 & 55,5 \\
Citrus amblicarpa & 24 & 03 & 6,0 \\
Microcitrus papuana & 60 & 0 & 0,0 \\
\hline
\end{tabular}

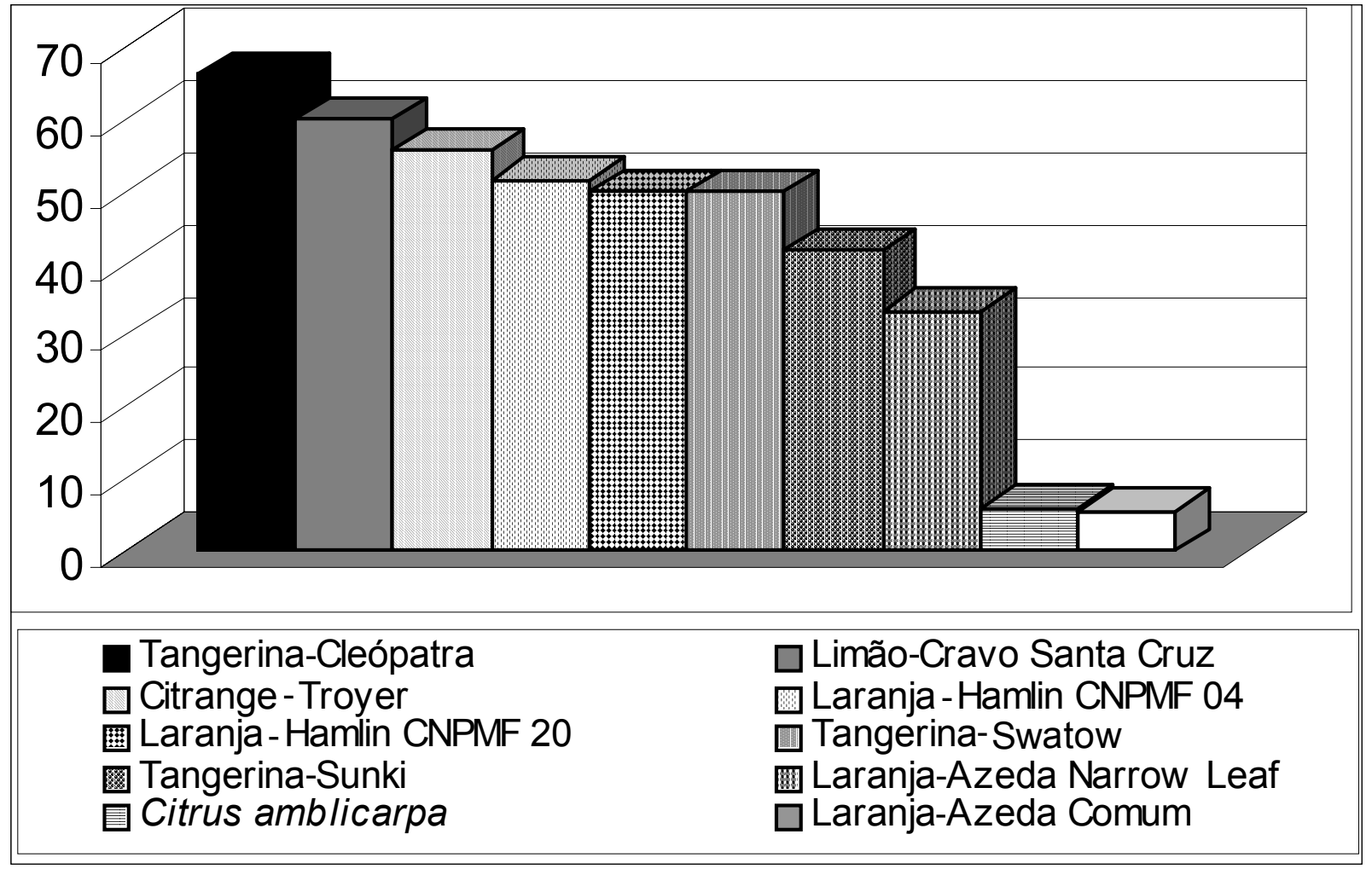

FIGURA 1 - Taxa (\%) de formação de calos a partir de óvulos não fertilizados extraídos de frutos imaturos de diversas variedades de citros. Embrapa Mandioca e Fruticultura. Cruz das Almas-BA, 1999. 
não se observou a formação de calos, enquanto, em Citrus amblicarpa e laranja-'Azeda Comum', a quantidade de óvulos que não formaram calos foi muito pequena: $4,0 \%$ e $5,5 \%$, respectivamente (Tabela 1). Nestas últimas, cabe acrescentar, os calos formados apresentaram pouco crescimento e oxidaram, sendo, portanto, descartados. De acordo com Moore (1985), este fato deve ter ocorrido devido a os explantes terem sido coletados numa fase em que o balanço hormonal endógeno era desfavorável à formação de calos. Além disso, segundo Kochba \& SpiegelRoy (1977), nas situações em que a calogênese foi baixa, esse comportamento pode ter sido devido ao uso desnecessário de reguladores de crescimento, que pode levar à oxidação e diminuição na velocidade de crescimento dos calos formados.

\section{CONCLUSÕES}

Considerando-se o conjunto de variedades cítricas estudadas, as seguintes conclusões podem ser obtidas: 1- Óvulos das tangerinas- 'Cleópatra' e 'Swatow', limão- 'Cravo Santa Cruz', laranja-'Hamlin' (CNPMF 04 e 20) e de citrange'Troyer' são altamente favoráveis à calogênese, com porcentuais iguais ou superiores a $50 \%$.

2 - A laranja-'Hamlin CNPMF 20' apresenta grande precocidade com relação ao início da calogênese.

\section{REFERÊNCIAS BIBLIOGRÁFICAS}

CASTLE, W.S. Citrus rootstocks. In: ROM, R.C.; CARLSON, R.F. (Ed.) Rootstocks for fruit crops. New York: Wiley, 1987. p. 361-399.

CASTLE,W.S.; TUCKER, D.P.H.;KREZDORN, A. H. ; YOUTSEY,C.O. Rootstocks for Florida Citrus: rootstock selection, the first step to sucers. 2. ed. Florida: University Florida, 1993.p.8.

DENG, XX.; GROSSER, J.W.; GMITTER Jr., F.G. Intergeneric somatic hybrid plants from protoplast fusion of Fortunella crassiflora 'Meiwa' with Citrus sinensis 'Valencia'. Scientia Horticulturae, Amsterdam, v. 49, p. 55-62, 1991.

GMITTER Jr., F.G.; MOORE, G.A. Plant regeneration from underveloped ovules and embryogenic calli of Citrus: embryo production, germination and plant survival. Plant Cell, Tissue and Organ Culture, Dordrecht, v.6, p.139-147, 1986.

GROSSER, J.W.; GMITTER Jr., F.G. Protoplast fusion and citrus improvement. In: JANICK, J.(Ed). Plant Breeding Reviews, New York, v.8, p.339-374, 1990a.

GROSSER, J.W.; GMITTER Jr., F.G. Wide-hybridization of citrus via protoplast fusion: progress, strategies and limitations. Horticultural Biotechnology, p.21-31, 1990 b.

GROSSER, J.W.; GMITTER .Jr., F.G.; CHANDLER, J.L. Intergeneric somatic hybrid plants of Citrus sinensis cv. Hamlin and Poncirus trifoliata cv. Flying Dragon. Plant Cell Reports,
Berlin, v.7, p.5-7, 1988.

GROSSER, J.W.; GMITTER Jr., F.G.; SESTO, F.; DENG, X.X.; CHANDLER, J.L Six new somatic citrus hybrid and their potential for cultivar improvement. Journal of the American Society for Horticultural Science, Alexandria, v.117. p.169-173, 1991.

GROSSER, J.W.; GMITTER Jr., F.G.; TUSA, N.; CHANDLER, J.L. Somatic hybrid plants from sexually incompatible woody species: Citrus reticulata and Citropsis gilletiana. Plant Cell Reports, Berlin, v.8, p.656-659, 1990.

GROSSER, J.W.; MOORE, G.A.; GMITTER Jr., F.G. Interespecific somatic hybrid plants from the fusion of 'Key lime' $(C$. aurantifolia) with 'Valencia' sweet orange (C. sinensis) protoplasts. Scientia Horticulturae, Amsterdam, n.39, p.23-29, 1989.

KOBAYASHI, S.; OHGAWRA, T.; OIYAMA, I.; ISHII, S.A Somatic hybrid obtained by protoplast fusion between navel orange (C. sinensis) and Satsuma mandarin $(C$. unshiu). Plant Cell, Tissue and Organ Culture, Dordecht, n.14, p.63-69, 1988.

KOCHBA, J.; SAFRAN, H. Adventive plants from ovules and nucelli in Citrus. Planta, Heidelberg, v.106, p.273-345, 1972.

KOCHBA, J.; SPIEGEL-ROY, P. Effect of culture media on embryoid formation from ovular callus of 'Shamouti'orange (Citrus sinensis). Journal of Plant Breeding, New York, v. 69, p.156-162, 1973.

KOCHBA, J.; SPIEGEL-ROY, P. The effect of auxins, cytokininis and inhibitors on embryogenesis in habituated ovular callus of the 'Shamouti' orange (Citrus sinensis). Zeitschrift fur Pflanzenphysiologie, Stuttgart, v.81, p.283-288, 1997.

LOUZADA, E.S.; GROSSER, J.W.; GMITTER Jr., F.G.; NIELSEN, B.; CHANDLER, J.L. Eigth new somatic hybrids citrus rootstocks with potential for improved disease resistence. HortScience, Alexandria, v.29, n.9, p.1033-1036, 1992.

MOORE, G.A. factors affecting in vitro embryogenesis from underveloped ovules of mature Citrus fruit. Journal of the American Society for Horticultural Science, Alexandria, v.110, p.66-70, 1985 .

MURASHIGE, T.; TUCKER, D.P.H. Growth factor requiriment of citrus tissue culture. In: INTERNACIONAL CITRUS SYMPOSIUM, 1., 1968. Riverside. Proceedings... Riverside: University of California, 1969. v.3, p.1155-1161.

OHGAWARA, T.; KOBAYASHI, S.; ISHII, S.; YOSHINOGA, K.; OIYAMA, I. Somatic hybridization in citrus: Navel orange (Citrus sinensis Osb.) and grapefruit (Citrus paradisi Macf.). Theoretical Applied Genetics, Berlin, v.71, p.609-612, 1989.

OLIVEIRA, R.P. de; MENDES, B.M.J.; TULMANN NETO, A. Obtenção e cultura de calos nucelares de limão-Cravo. Revista Brasileira de Fisiologia Vegetal, Brasília, v.6, n.2, p.115-119, 1994. 
SPIEGEL-ROY, P.; KOCHBA, J. Embryogenesis in Citrus tissue cultures. Advances in Biochemical Engineering, Berlin, v.16, p.27-48, 1980 .

SPIEGEL-ROY, P.; VARDI, A. Citros. In: AMMIRATO, P.V.; EVANS, D.A.; SHARP, W.R.; YAMADA, Y. (Ed.) Handbook of Plant Tissue Culture; crop species. New York. Mac Millan, 1984. v.3,p.355-372.

TUSA, N.; GROSSER, J.G.; GMITTER Jr., F.G. Plant regeneration of 'Valencia' sweet orange, 'Femminello' lemon, and the interspecific somatic hybrid following protoplast fusion. Journal of the American Society for Horticultural Science, Alexandria, v.115, n.6, p.1043-1046, 1990.

VARDI, A.; SPIEGEL-ROY, P.; GALUN, E. Plant regeneration from Citrus protoplast: variability in methodological requeriments among cultivars and species. Theoretical and Applied Genetics, Berlin, v.62, p.171-176, 1982. 